\title{
OPERATOR FUNCTIONS ON CHAOTIC ORDER INVOLVING ORDER PRESERVING OPERATOR INEQUALITIES
}

\section{TAKAYUKI FURUTA}

Abstract. An operator $T$ is said to be positive (denoted by $T \geqslant 0$ ) if $(T x, x) \geqslant 0$ for all vectors $x$ in a Hilbert space, and $T$ is said to be strictly positive (denoted by $T>0$ ) if $T$ is positive and invertible. Let $\log A \geqslant \log B$ and $r_{1}, r_{2}, \ldots, r_{n} \geqslant 0$ and any fixed $\delta \geqslant 0$, and

$$
p_{1} \geqslant \delta, \quad p_{2} \geqslant \frac{\delta+r_{1}}{p_{1}+r_{1}}, \ldots, p_{k} \geqslant \frac{\delta+r_{1}+r_{2}+\ldots+r_{k-1}}{\mathfrak{q}[k-1]}, \ldots, p_{n} \geqslant \frac{\delta+r_{1}+r_{2}+\ldots+r_{n-1}}{\mathfrak{q}[n-1]} .
$$

Let $\mathfrak{F}_{n}\left(p_{n}, r_{n}\right)$ be defined by

$$
\mathfrak{F}_{n}\left(p_{n}, r_{n}\right)=A^{\frac{-r_{n}}{2}} \mathbb{C}_{A, B}[n]^{\frac{\delta+r_{1}+r_{2}+\ldots+r_{n}}{\mathfrak{q}[n]}} A^{\frac{-r_{n}}{2}} .
$$

Then the following inequalities (i), (ii) and (iii) hold:

(i) $A^{\frac{p_{k-1}}{2}} \mathfrak{F}_{k-1}\left(p_{k-1}, r_{k-1}\right) A^{\frac{p_{k-1}}{2}} \geqslant \mathfrak{F}_{k}\left(p_{k}, r_{k}\right)$ for $k$ such that $1 \leqslant k \leqslant n$,

(ii) $B^{\delta} \geqslant A^{\frac{-r_{1}}{2}}\left(A^{\frac{r_{1}}{2}} B^{p_{1}} A^{\frac{r_{1}}{2}}\right)^{\frac{\delta+r_{1}}{p_{1}+r_{1}}} A^{\frac{-r_{1}}{2}}$

$$
\begin{aligned}
\geqslant & A^{\frac{-\left(r_{1}+r_{2}\right)}{2}}\left\{A^{\frac{r_{2}}{2}}\left(A^{\frac{r_{1}}{2}} B^{p_{1}} A^{\frac{r_{1}}{2}}\right)^{p_{2}} A^{\frac{r_{2}}{2}}\right\}^{\frac{\delta+r_{1}+r_{2}}{\left(p_{1}+r_{1}\right) p_{2}+r_{2}}} A^{\frac{-\left(r_{1}+r_{2}\right)}{2}} \\
\geqslant & A^{\frac{-\left(r_{1}+r_{2}+r_{3}\right)}{2}}\left\{A^{\frac{r_{3}}{2}}\left[A^{\frac{r_{2}}{2}}\left(A^{\frac{r_{1}}{2}} B^{p_{1}} A^{\frac{r_{1}}{2}}\right)^{p_{2}} A^{\frac{r_{2}}{2}}\right]^{p_{3}} A^{\frac{r_{3}}{2}}\right\} \frac{\delta+r_{1}+r_{2}+r_{3}}{\left\{\left(p_{1}+r_{1}\right) p_{2}+r_{2}\right\} p_{3}+r_{3}} A^{\frac{-\left(r_{1}+r_{2}+r_{3}\right)}{2}} \\
& \vdots \\
\geqslant & A^{\frac{-\left(r_{1}+r_{2}+\ldots+r_{n}\right)}{2}} \mathbb{C}_{A, B}[n]^{\frac{\delta+r_{1}+r_{2}+\ldots+r_{n}}{q[n]}} A^{\frac{-\left(r_{1}+r_{2}+\ldots+r_{n}\right)}{2}},
\end{aligned}
$$

(iii) $\mathfrak{F}_{n}\left(p_{n}, r_{n}\right)$ is a decreasing function of both $r_{n} \geqslant 0$ and $p_{n} \geqslant \frac{\delta+r_{1}+r_{2}+\ldots+r_{n-1}}{\mathfrak{q}[n-1]}$, where $\mathbb{C}_{A, B}[n]$ and $\mathfrak{q}[n]$ are defined as follows:

$$
\mathbb{C}_{A, B}[n]=A^{\frac{r_{n}}{2}}\left\{A^{\frac{r_{n-1}}{2}}\left[\ldots A^{\frac{r_{3}}{2}}\left\{A^{\frac{r_{2}}{2}}\left(A^{\frac{r_{1}}{2}} B^{p_{1}} A^{\frac{r_{1}}{2}}\right)^{p_{2}} A^{\frac{r_{2}}{2}}\right\}^{p_{3}} A^{\frac{r_{3}}{2}} \ldots\right]^{p_{n-1}} A^{\frac{r_{n-1}}{2}}\right\}^{p_{n}} A^{\frac{r_{n}}{2}}
$$

and

$$
\mathfrak{q}[n]=\left[\ldots\left\{\left(p_{1}+r_{1}\right) p_{2}+r_{2}\right\} p_{3}+\ldots r_{n-1}\right] p_{n}+r_{n} .
$$

We remark that (ii) can be considered as "a satellite inequality to chaotic order".

Mathematics subject classification (2010): 47A63. order.

Keywords and phrases: Löwner-Heinz inequality, order preserving operator inequality and chaotic

\section{REFERENCES}

[1] T. ANDo, On some operator inequality, Math. Ann. 279 (1987), 157-159.

[2] T. Ando AND F. HiaI, Log majorization and complementary Golden-Thompson type inequalities, Linear Alg. and Its Appl. 197, 198 (1994), 113-131.

[3] R. Bhatia, Positive Definite Matrices, Princeton Univ. Press, 2007. 
[4] M. FuJII, Furuta's inequality and its mean theoretic approach, J. Operator Theory 23 (1990), 67-72.

[5] M. FujII AND E. KAMEI, Mean theoretic approach to the grand Furuta inequality, Proc. Amer. Math. Soc. 124 (1996), 2751-2756.

[6] M. FujiI, T. FurUtA AND E. KAMEI, Furuta's inequality and its application to Ando's theorem, Linear Alg. Appl. 179 (1993), 161-169.

[7] M. Fuji, A. Matsumoto And R. NaKamoto, A short proof of the best possibility for the grand Furuta inequality, J. of Inequal. and Appl. 4 (1999), 339-344.

[8] M. FujiI, E. KAMEI AND R. NAKAmoto, On a question of Furuta on chaotic order, Linear Algebra Appl. 341 (2002), 119-127.

[9] M. FujiI, E. Kamei And R. NaKamoto, On a question of Furuta on chaotic order II, Math. J. Okayama Univ. 45 (2003), 123-131.

[10] T. FURUTA, $A \geqslant B \geqslant 0$ assures $\left(B^{r} A^{p} B^{r}\right)^{1 / q} \geqslant B^{(p+2 r) / q}$ for $r \geqslant 0, p \geqslant 0, q \geqslant 1$ with $(1+2 r) q \geqslant$ $p+2 r$, Proc. Amer. Math. Soc. 101 (1987), 85-88.

[11] T. FURUTA, Elementary proof of an order preserving inequality, Proc. Japan Acad. 65 (1989), 126.

[12] T. FuRUTA, Applications of order preserving operator inequalities, Operator Theory: Advances and Applications $\mathbf{5 9}$ (1992), 180-190.

[13] T. FurutA, An extension of the Furuta inequality and Ando-Hiai log majorization, Linear Alg. and Its Appl. 219 (1995), 139-155.

[14] T. FURUTA, Simplified proof of an order preserving operator inequality, Proc. Japan Acad. 74, Ser. A (1998), 114.

[15] T. FuRUTA, Results under $\log A \geqslant \log B$ can be derived from ones under $A \geqslant B \geqslant 0$ by Uchiyama's method associated with Furuta and Kantorovich type operator inequalities, Math. Inequal. Appl. 3 (2000), 423-436.

[16] T. FURUTA, Invitation to Linear Operators, Taylor \& and Francis, 2001, London.

[17] T. FURUTA, $A \geqslant B>0$ assures $A^{1+r-t} \geqslant\left\{A^{\frac{r}{2}}\left(A^{\frac{-t}{2}} B^{p} A^{\frac{-t}{2}}\right) A^{\frac{r}{2}}\right\}^{\frac{1+r-t}{(p-t) s+r}}$ for $t \in[0,1], r \geqslant t, p \geqslant 1$, $s \geqslant 1$ and related inequalities, Archives of Inequalities and Applications 2 (2004), 141-158.

[18] T. FURUTA, Further extension of an order preserving operator inequality, J. Math. Inequal. 2 (2008), 465-472.

[19] T. FurUta AND M. Hashimoto AND M. ITO, Equivalence relation between generalized Furuta inequality and related operator functions, Scientiae Mathematicae 1 (1998), 257-259.

[20] T. Furuta, M. YANAGIDA AND T. YAmAZAKI, Operator functions implying Furuta inequality, Math. Inequal. Appl. 1 (1998), 123-130.

[21] E. HeInZ, Beiträge zur Störungsteorie der Spektralzerlegung, Math. Ann. 123 (1951), 415-438.

[22] M. ITO AND E. KAMEI, Mean theoretic approach to a further extension of grand Furuta inequality, J.Math. Inequal. 4 (2010), 325-333.

[23] S. IZUmino, N. NAKAMURA AND M. Tominaga, Mean theoretic operator functions for extensions of the grand Furuta inequality, Sci. Math. Jpn. 72 (2010), 157-163.

[24] E. KAMEI, A satelite to Furuta's inequality, Math. Japon. 33 (1988), 883-886.

[25] E. KAMEI, Parametrized grand Furuta inequality, Math. Japon. 50 (1999), 79-83.

[26] F. Kubo And T. Ando, Means of positive linear operators, Math. Ann. 246 (1980), 205-224.

[27] K. LÖWNER, Über monotone Matrixfunktionen, Math. Z. 38 (1934), 177-216.

[28] G. K. Pedersen, Some operator monotone functions, Proc. Amer. Math. Soc. 36 (1972), 309-310.

[29] K. Tanahashi, Best possibility of the Furuta inequality, Proc. Amer. Math. Soc. 124 (1996), 141146.

[30] K. Tanahashi, The best possibility of the grand Furuta inequality, Proc. Amer. Math. Soc. 128 (2000), 511-519.

[31] M. UChiYAma, Some exponential operator inequalities, Math. Inequal. Appl. 2 (1999), 469-471.

[32] T. YAMAZAKI, Simplified proof of Tanahashi's result on the best possibility of generalized Furuta inequality, Math. Inequal. Appl. 2 (1999), 473-477.

[33] J. YuAn AND Z. GaO, Classified construction of generalized Furuta type operator functions, Math. Inequal. Appl. 11 (2008), 189-202.

[34] C. YANG AND Y. WANG, Further extension of Furuta inequality, J. Math. Inequal. 4 (2010), 391-398. 